\title{
The grammar of politics: A brief history of legislative language in Britain
}

\section{Matthew Williams}

\section{PLEASE NOTE:}

This is the peer reviewed version of the following article: The grammar of politics: A brief history of legislative language in Britain, which will be published in final form at http://www.politicalquarterly.org.uk. This article may be used for non-commercial purposes in accordance with Wiley Terms and Conditions for Self-Archiving. 


\section{ABSTRACT}

Legislative language is a crucial, yet somewhat overlooked element of British politics. So how has the language of British legislation changed over the past century? All 191,080 pages of legislation enacted between 1900 and 2015 were assessed for changes in the quantity of legislation. And, 5,878 sections of legislation from 1920 to 2015 were analysed for changes to the quality of language. Parts of speech that affect the subject, object and verb of sentences were recorded, giving a novel long-term study of indeterminacy in legislative language. Findings show that interpreting legislation became increasingly dependent on circumstance and discretion after the war. Change further accelerated after 1975. This reflected a widening gap between public demands placed on government power, and the difficulties faced in accommodating these demands.

KEYWORDS: Language, legislation, policy, meaning, sovereignty.

\section{INTRODUCTION}

With no higher law constitution, parliamentary legislation is the final word on how powers, duties and rights are distributed in Britain. But how clear and meaningful are the sovereign's words? Specifically, how has the language of legislation changed over the past century? The headline is that legislative language with indeterminate meaning has been increasingly enacted over the past seventy years. When legislative language is indeterminate, the same words can be used to address a variety of problems. It is language that captures neither reality, nor desire, but is left open to broad interpretation. This allows the meaning of words to be adapted in response to unanticipated circumstances and in accordance with an individual's discretion.

An early shift in legislative language began post-war. Given the timing, it was likely the result of 
changes in demands for and the available supply of public power. Indeterminate language allowed governments to address complex and changeable demands, whilst adapting to circumstances that were increasingly beyond their control. Being indeterminate, the meaning of language could also be resolved by an individual's discretion. This capacity was especially welcome to those who wished to provide or withhold public services in specific cases, without the need for explicit parliamentary authorisation. Indeterminacy in language was therefore initially enacted by necessity, but increasingly became a choice, driven by the desire for enhanced discretion. Beyond the benefits to government, private citizens with the resources to contest the meaning of words will also benefit from indeterminacy in law.

The findings of this study describe extraordinary changes. Three parts of speech were analysed to consider, respectively, how indeterminacy was introduced to the object, subject and verb of legislative sections. Of the 992 sections enacted in 2015, 724 used conditional language, where the object of the sentence was underspecified and had to be determined by contextual information (as in: if $a$, and/or $b$ is present, then do $c$ or $d$ ). Also, 615 sections used adjectives or adverbs (such as 'reasonable' and 'necessary') that qualified the primary noun. And, finally, 180 sections granted discretion to an agent of Parliament in broad terms through the modal verb 'may' (as in 'the Secretary of State may act') rather than the more determinate modal verbs 'will' or 'shall'. In real terms, the increases are by a factor of nine over ninety-five years.

This essay aims to solve an important problem: how to analyse legislative language through time. The meaning of words depends on context. As such, studying what words have meant through time is impossible without also knowing the context. But, meaningfulness can be 
measured. This is because the rules of grammar are more stable. ${ }^{i}$ The parts of speech measured for this essay are especially dependent on context and interpretation to be meaningful. By measuring these, we will have a good indication of whether legislative language had meaning authorised by Parliament, or was indeterminate. Observations were limited to the UK, but the findings are of wider interest. Inexplicable and unpredictable policy decisions are partly responsible for voter disengagement across the democratic world. If election promises are set in indeterminate language it suggests there is a gap between what is said and what will or can be done.

The essay begins by unpacking the question. What is indeterminate legislative language? And what forms does the language of legislation increasingly take? Two new data sets are then presented, describing changes in the quantity and quality of legislative language. Every page of legislation from 1900 to 2015 was assessed for the first data set. This totals 191,080 pages across 6,694 statutes. For the second data set, 5,878 sections of primary legislation from 1920 to 2015 were analysed. Following the data analysis is discussion of the findings. The essay ends by offering solutions.

\section{GOVERNED BY CIRCUMSTANCE AND DISCRETION}

Politicians juggle voters' demands, market pressure, media scrutiny, and the interests of foreign 
governments; all the while under time constraints with imperfect information. Committing policy to determinate legislative language is far from easy therefore. So, what even is determinate language? For legislation, it is clear instructions on when, how and why to distribute powers, duties and rights. Vivien Schmidt has argued that clear instruction depends on a 'logic of communication, ii According to this, communication begins with principles, from which concrete decisions are extrapolated. Rather like a funnel, broad ambitions are narrowed to specific choices. The links between intention and action will then be obvious. Conversely, the logic breaks if there is any disconnect between intention and action. This can happen if, instead of starting with a principle, decisions are taken and justified after the fact. In legislative language, this can be achieved with indeterminate language that can mean what best suits a given circumstance and at the discretion of an agent. Such language can accommodate unanticipated events, such as market jitters or diplomatic pressure. It nonetheless can weaken society's role in deciding what principles are preferred, regardless of what may happen.

Let us consider some examples of indeterminate and determinate legislative language. The following examples cover language used to grant powers, duties and rights in turn. For each comparison, the differences lie in three important parts of speech: i) conditions imposed on how context affects meaning, ii) noun-qualifying adjectives and adverbs, and iii) the use of modal verbs enabling an agent of Parliament to act with discretion. All parts of speech affect meaning, but these three are especially important in opening up the range of possible interpretations. They also cover the three core components of syntax in the following ways: i) the object of a sentence is changeable by imposing conditions on identifying and classifying what in fact the object of policy is, ii) the subject of a sentence is changeable by qualifying its meaning with adjectives or 
adverbs, and iii) the verb 'may' grants discretion as to the timing and extent of a decision, in contrast to the more restrictive modal verbs 'will' or 'shall'. Of course, adjectives and adverbs can transform the object of a sentence, and conditions can affect the subject. But, the subject of a section is that which is most affected by qualifying adjectives or adverbs, and the object of a section is most often transformed by conditions on interpretation. This can be seen in the following examples.

First, the British Nationality Act 1948 offers an example of determinate language. Parliament authorised the meanings of citizenship and subjecthood:

'1(1) Every person who... is a citizen of the United Kingdom and Colonies... shall by virtue of that citizenship have the status of a British subject.'

This language defines key concepts without equivocation. The nouns, 'citizen' and 'subject' are further defined later in the Act, such that an individual could understand their status simply by reading the legislation. It is language derived from straightforward principles as to who should be recognised as citizens and subjects. Compare it to a section from the Immigration Act 1971:

'3(1) ... where a person is not patrial-

(a) he shall not enter the United Kingdom unless given leave to do so in accordance with this Act;

(b) he may be given leave... either for a limited or for an indefinite period;

(c) leave... may be given subject to conditions restricting his employment or occupation... 
or requiring him to register with the police, or both.'

The conditional language (unless, either, or) and modal verbs used (may) allow the language to be applied to a range of circumstances with discretion. An individual seeking leave could not easily predict whether it will be granted or what conditions may be imposed. This language does not capture any clear vision of how immigration should be managed. Instead it enables governments to manage immigration as they see fit, given various domestic and international constraints.

The specific effect of the modal verb 'may' on government discretion can be observed even more sharply in section 28 of the Digital Economy Act 2010:

'(2) In subsection (1) for "must do all that they can to" substitute "may"...

(4) Accordingly, in the heading of the section, for "Duty" substitute "Power".'

Changing from 'must do' to 'may' has made the language indeterminate. Rather than being obligatory, the use of the legislation is discretionary. Delegating power to agents is essential for effective government. But, the verb 'may' significantly broadens the discretion of agents. By using 'may', Parliament delegates not only a specific power, but the ability to decide how, when and why a power can be used.

Next, let us consider homelessness legislation and the duties imposed on local housing officers. First, the Homeless Persons (Priority Need) (Wales) Order 2001 defines those with priority need 
for housing assistance:

'5. A person... who has been subject to domestic violence or is at risk of such violence, or if he or she returns home is at risk of domestic violence.'

Conditions (or, if) and adjectives (domestic) create a modicum of uncertainty here. Even the nouns 'risk' and 'violence' are not unambiguous. However, the duty is clear. Those suffering from domestic violence in Wales can expect to be given priority in housing allocations. Meanwhile, England has adopted an almost identical provision, save for the addition of an adjective and an adverb. These change the duty, such that victims of domestic violence in England cannot easily predict whether they will be prioritised. The Homelessness (Priority Need for Accommodation) (England) Order 2002 describes priority need as follows:

'6. A person who is vulnerable... by reason of violence from another person or threats of violence from another person which are likely to be carried out.'

The Welsh policy offers universal application to victims of domestic violence, whilst the English version can be varied depending on circumstance. Housing officers in England need to assess whether one victim of violence is more or less vulnerable than another, and whether violence or threats of violence are likely. After these two homelessness laws were introduced, England saw a sharp dip in the number of people recognised as being in priority need as compared to Wales. ${ }^{\text {iii }}$ Ultimately the Supreme Court had to define the word 'vulnerable' to remove some of the uncertainty. ${ }^{\text {iv }}$ 
The final set of comparisons come from anti-discrimination laws. These laws contain rights for citizens. First, consider the Race Relations Act 1968:

'1(1) a person discriminates against another if ... he treats that other... less favourably than he treats or would treat other persons

(2) It is hereby declared that... segregating a person... is treating him less favourably'

This language uses adverbs (favourably) and imposes conditions on interpretation (if, or). But, importantly, the language also declares what 'less favourably' means with regard to segregation ('it is hereby declared'). Compare this to the Equality Act 2010:

'159(1) This section applies if a person reasonably thinks that -

(a) persons who share a protected characteristic suffer a disadvantage connected to the characteristic, or

(b) participation in an activity by persons who share a protected characteristic is disproportionately low.'

Here we see that indeterminate language can benefit private individuals. Employers and employees may, for instance, fight over their preferred interpretations of the words used. The adverbs 'reasonably' and 'disproportionately' invite users of the law to find a yardstick for comparison, because there is no fixed definition to the words. 
Indeterminacy creates a mode of communication that does not rely on logic, as Schmidt has described it, but on analogic. Put literally, analogic means 'up to a standard'. This is definition by approximation. Experience fleshes out the meaning of words like 'disproportionately', and powerful individuals 'may' decide which route to take through the ifs, ors and unlesses of modern legislation. As a manifestation of sovereign power, this mode of communication is especially interesting. The sovereign creates a scaffolding for determining power but does not decide what powers absolutely are or should be. The language used marks a shift in model, from a negative sovereignty where power was used to constrain, towards a positive sovereignty where power was used to enable; albeit under conditions of uncertainty.

\section{METHODOLOGY AND FINDINGS}

Returning to the question, how has the language of legislation changed over the past century? Before assessing changes to quality, let us consider quantity. Both are linked. It could be assumed that longer laws are more detailed, and hence more determinate. ${ }^{\mathrm{v}}$ But, length can also signal a framework for adapting words to new contexts. A simple, declaratory law can take the form 'if $x$ then $y$ '. Whereas to establish a capacity to adapt to context takes many more words: 'if $x$ or $y$, then $z$, else if $a, b$ or $c^{\prime}$. The irony is that even governments set on cutting red tape have done so by writing vastly more law. The following graph describes the changes over 115 years. 
Figure 1: Parliament's legislative output, 1900-2015

6000

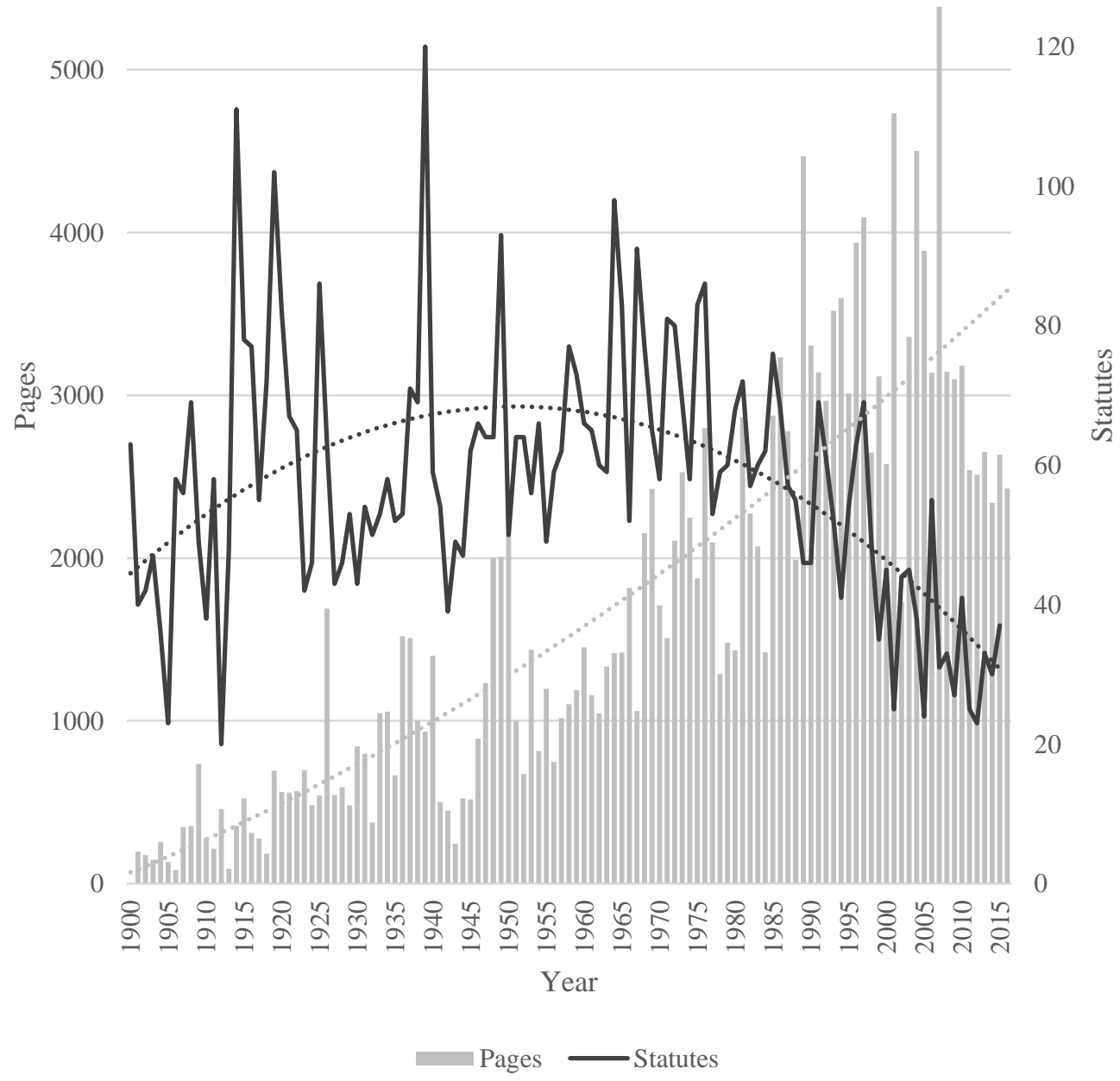

There were only 82 pages of legislation enacted in 1905, but 5,388 pages in 2006 . The Income and Corporation Taxes Act 1988 is 1,317 pages long on its own, making it sixteen times the entire output of 1905. Despite the increasing number of pages, there have been fewer statutes enacted. The peak came in 1939 with 120 statutes, and a recent trough was 2005 with 24 statutes. Although, only 20 statutes were enacted in 1912 amidst battles over Irish Home Rule and women's suffrage. The pattern is towards fewer statutes of greater length. The average statute in 1900 was three pages long. In 2005 the average statute was 131 pages long. These data touch the 
surface. They consider public acts of Parliament. Also of importance are private acts, hybrid acts and secondary legislation.

And what of the clarity of this language? Figure 2 displays results from coding just under 6,000 sections of primary legislation across ninety-five years. Observations of significant parts of speech were recorded by hand with a simple binary: present/absent. A record was taken if a section contained language whose meaning was conditional on context, such as in sentences using if with the Boolean operators or, and, not. Also recorded was the use of noun-qualifying adjectives or adverbs, and the modal verb 'may'. The observations were then verified by a computer text reading program. The hand coding results are displayed as they are the more discerning. For instance, a computer would record every single use of the verb 'may'. But the verb can be used with a determinate meaning, especially when granting or withholding permission; as in ' $x$ may own' or ' $y$ may not leave'.

Counting the mere presence or absence of conditions, adjectives or modal verbs in a section, some of which are very long, may seem overly simplifying. But the focus was on the dominant sentence clause, rather than supplementary matters. Computer coding could not easily discriminate in this way, but does provide a check for the trends observed. Every single section of legislation enacted in 1920, 2010 and 2015 was analysed. The starting date of 1920 was chosen because it provides almost a century of data, but both 1910 and 1915 were such unusual years in British politics that they could not provide a reliable baseline. Between 1920 and 2010, measurements were taken from samples of five percent of all sections. These samples were taken at five-year intervals from 1925 to $2005 .^{\text {vi }}$ 


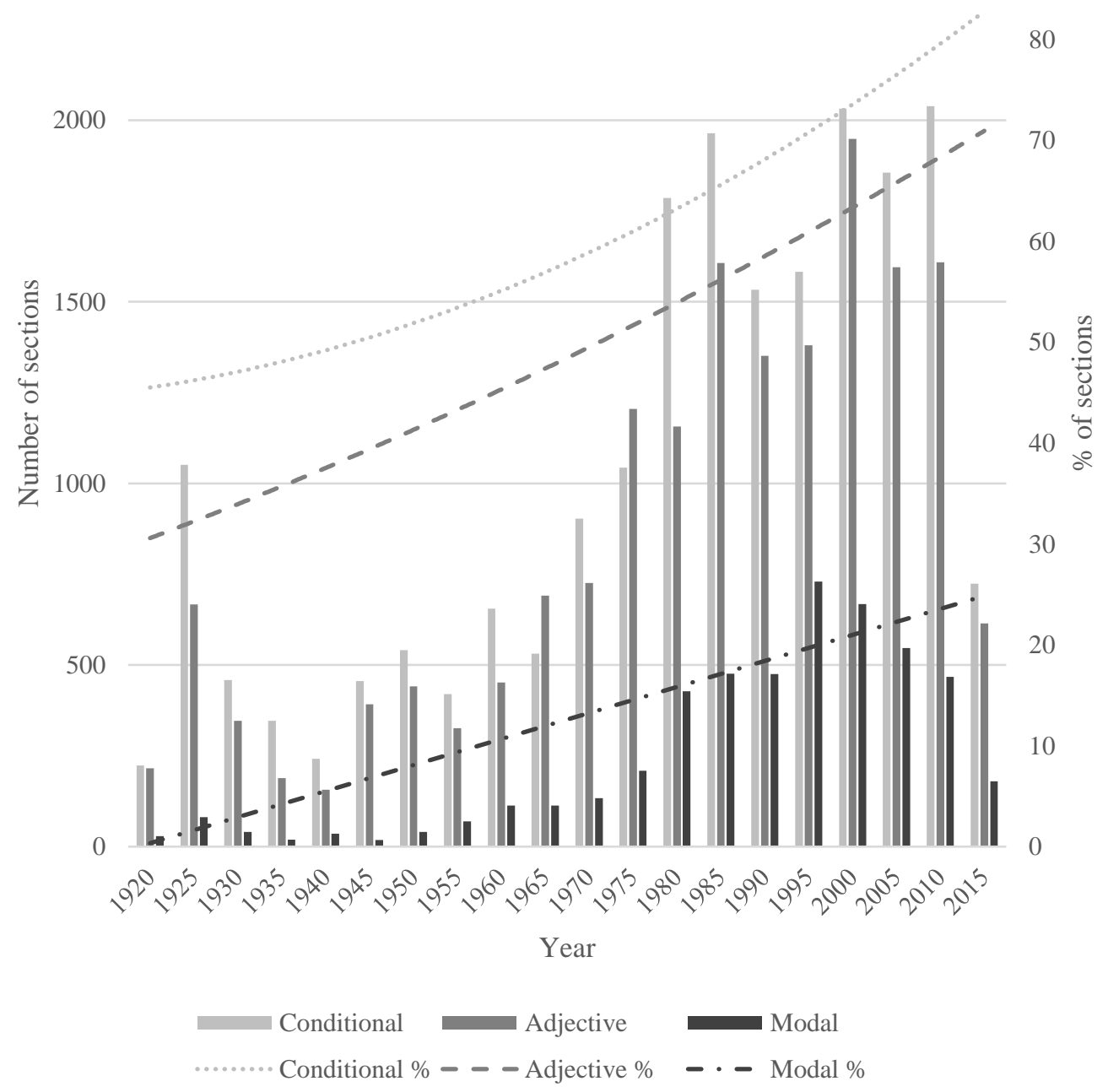

Focussing first on the secondary y-axis, we can see that the vast majority of legislation in 2015 contained conditional language and adjectives. The dotted and dashed lines used do not present the exact figures for each year, but rather the smoothed trends. These lines show that legislation was qualitatively different ninety-five years ago. Indeed, over eighty percent of sections in 2010 , the peak year, had conditional parts of speech. Conditional language has seen the greatest use, but use of adjectives and the modal verb 'may' have had similar upward trajectories. Whilst conditional language was not uncommon in 1920, it was recorded in just $31 \%$ of sections. From 
then on, conditions were imposed on around half of all sections enacted until 1980 when the incidence shot to $71 \%$. A majority of sections containing adjectives or adverbs was not observed until 1975, with 52\% incidence. Usage then jumped in 1990 to $74 \%$. Legislation changed from having under one-third of sections containing adjectives or adverbs, to three-quarters. The modal verb 'may' also underwent a significant increase in use, albeit utilised around $40-50 \%$ less often than conditions and adjectives or adverbs. Just 4\% of sections in 1920 relied on the verb. This compares to $36 \%$ of sections in 1995 , the peak year.

Changes in real terms are even more striking. In 1920 there were 223 sections containing conditions, 216 sections containing adjectives, and 29 using the modal verb 'may'. By 2010 these figures were up to 2,039, 1,609 and 467 respectively. In 2015 there was a sharp drop in real terms $(724,615$ and 180 respectively), although there was barely any change in the proportionate incidence $(72 \%, 63 \%$ and $18 \%$ respectively). The dip in quantity can be explained by the coalition government limping to an election in 2015, followed by a Conservative government with a slim majority pursuing relatively few legislative goals.

The peaks in indeterminate legislative language came at times of political uncertainty. At these times, a gap grew between what voters wanted and what governments could, or wanted to, provide. The mid-20s saw a spike in the enactment of indeterminate language, and the greatest rates of change were recorded between 1960 and 2000, as Figure 3 demonstrates. Also of note from Figure 3 are the sharp changes in direction, from indeterminate to more determinate language recorded when Conservative and Labour governments exchanged power. See, for instance, the decreased proportionate use of indeterminate language recorded in 1965, 1975, and, 
to a lesser extent, 2000. Conversely, the move from Labour to Conservative governments, and changes of Conservative Prime Minister were coincident with increased use of indeterminate language; see 1970, 1980 and 1990. So, the greatest use of indeterminate language coincides with Conservative rule in the late twentieth century. Albeit, the three forms of indeterminacy did not change uniformly, and Labour governments in 1965, 1975 and 2000 were coincident with an increased use of adjectives and adverbs.

Figure 3: Rates of change in the use of indeterminate language in legislation

40

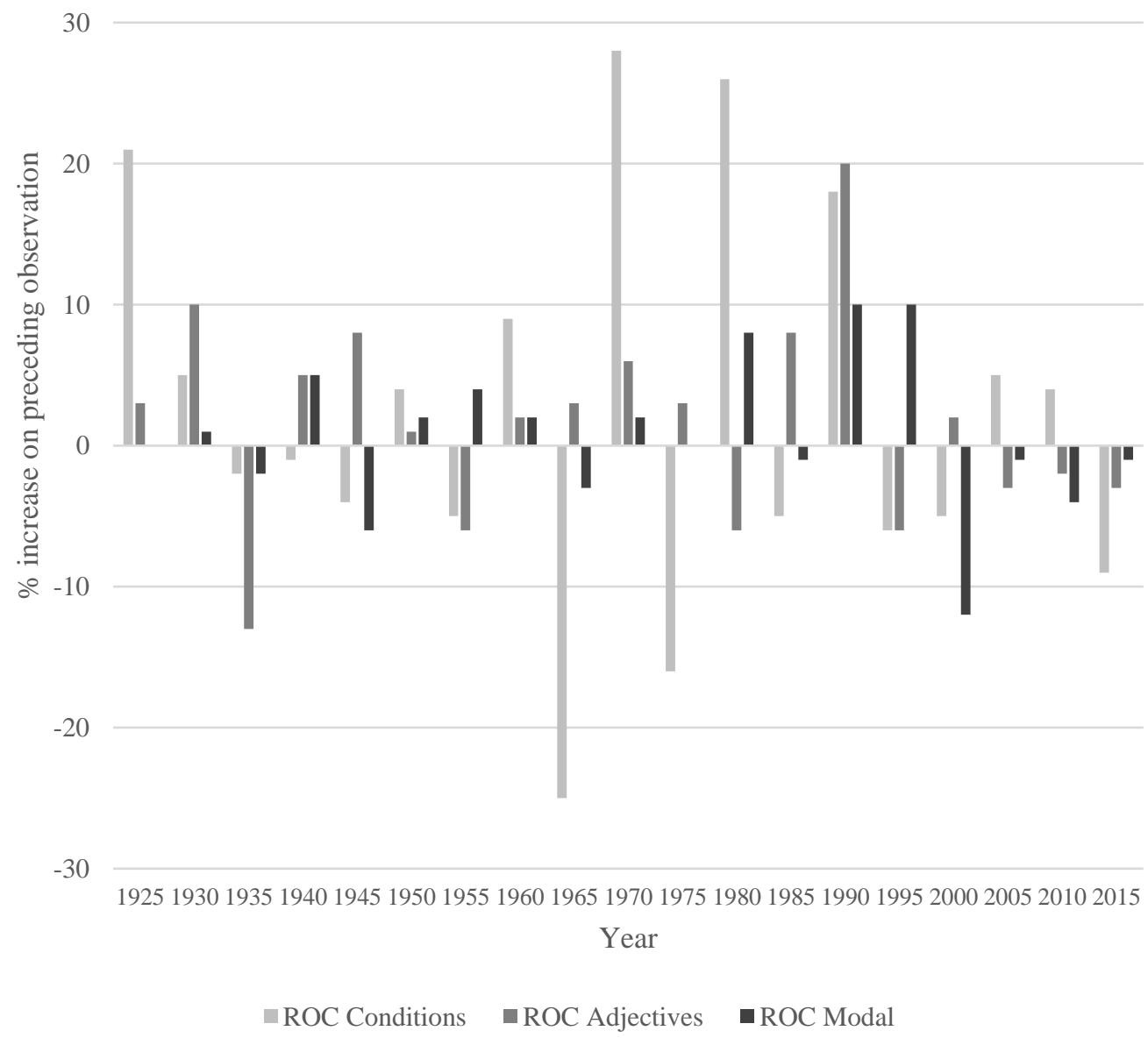




\section{DISCUSSION}

The language of British sovereignty has changed significantly over time. In modern legislation, the meaning of words is increasingly left open to interpretation. Words are then fought over outside Parliament, rather than being settled at the despatch box and subject to the ballot box. Recall the powers conferred by the Immigration Act 1971:

(b) [An immigrant] may be given leave... either for a limited or for an indefinite period;

(c) leave... may be given subject to conditions restricting his employment...'

This language cannot be clarified by a good dictionary. It gives the Home Secretary the power to tailor the law to a wide range of individuals in many and varied contexts. So why has determinate legislative language become increasingly rare? No simple explanation is available. And yet, the historical perspective allows us to narrow down some of the most impactful factors. The use of indeterminate language rose in the 1950s and accelerated from the 1960s. This language was more prominently used by Parliaments with Conservative majorities. These observations point to historical and ideological forces at work. Also, intuitively, Britain's constitution played its part. Whilst indeterminate legislative language is not unique to the UK, ${ }^{\text {vii }}$ its use is facilitated by elections that exaggerate the popularity of winning parties. Strong singleparty governments can then dominate law-making, without the constraints of a written constitution. 
Nonetheless, history and ideology operated in two overlapping phases. In other words, indeterminate language was at first adopted more by necessity, but later by choice. The role of history came with Britain's relative economic decline. Bankruptcy after the war, the rising power of the US and the end of empire all undermined governments' capacity to act. British citizens, meanwhile, had had their expectations of what government could and should provide inflated by the post-war welfare state. Demands for public goods rose when the ability to supply increasingly depended on uncertain global forces. Balancing trade, securing the value of the pound, enhancing productivity and competitiveness all depended, in particular, on forces beyond the immediate control of government or Parliament. Governments therefore instructed Parliament to frame a growing range of policy competencies in loose language. But, through the 1970s, focus on what the public wanted gradually switched to an increasing interest in what government could provide. From 1979 the interest in matters of supply became increasingly enthusiastic and driven in part by ideology.

The Thatcher governments and their successors saw the state as a facilitator of private enterprise. The state was to be 'rolled back' to make way for capitalism. This was a neoliberal approach to economic management, but with some uniquely British characteristics. ${ }^{\text {vii }}$ First was the unwillingness to abandon the welfare state. The NHS, public housing, pensions and benefits were opened up to market forces, but none were entirely taken off the public books. Second, was a dose of patriotism. Policy should boost national autonomy and civic pride. As such, the state was not rolled back in terms of national defence and internal security. Indeed, the state adopted significantly illiberal means to fight enemies foreign and domestic. The third characteristic of 
British neoliberalism underpinned the other two. The power of the core executive was enhanced. ${ }^{\text {ix }}$ The economy would be freed by a stronger state smashing barriers to competitiveness. ${ }^{\mathrm{x}}$ All of these attributes of British neoliberalism favoured legislation that could be adapted to circumstance with discretion. Less attractive was tight parliamentary control of what was possible in law.

A gap between public demand and what the government could or was willing to supply has therefore been reflected in the language of legislation. Using indeterminate language allowed policy makers to claim that they were responding to increasingly complex demands, whilst giving discretion to manage the various constraints on supply. The primary implication is that what policy has meant depended on who controlled the words. In his 1861 history of the rule of law, Henry Maine described a move from 'status to contract' in legal systems. ${ }^{\mathrm{xi}}$ Charismatic rulers, he argued, were tamed by rational laws. But with legislation lacking determinate meaning, there is no fixed contract. Status can once again dominate. This is a regressive step for parliamentary democracy. It is especially bleak for those concerned with equality and justice. The weakest will least likely have the status or resources needed to fight for their preferred interpretations of indeterminate language. How does an immigrant know what conditions will be imposed on her residence? How does a person fleeing violence prove she is vulnerable? How can a victim of discrimination assert that their involvement in an activity is 'disproportionately low'? Furthermore, those who lose out from public policy will not be able to accept the reasons for their losing. ${ }^{\text {xii }}$ This breeds resentment at the seeming arbitrariness of policy. This has aptly been described as post-democratic politics. Leadership is less founded on public debate and more on the perceived requirements of circumstance and individual whim. ${ }^{\text {xii }}$ To get here, Parliament has 
written vastly more legislation than it did a century ago, but with increasingly indeterminate language.

\section{CONCLUSION}

Parliamentary legislation is increasingly indeterminate. This is far from being a modern phenomenon, with an upward trend recorded over the past seventy years. Legislative language has moved away from a 'logic of communication' and instead has built meaning through analogy. In other words, what the law enables has been worked out through experience and by regression to a central tendency of meaning. Conservative governments relied the most on indeterminate legislative language. Although, so too did the Labour governments after 1997. A 'what matters is what works' approach can be effective given the complexities of modern governance, but there is a balance to be struck. Some clear guidance on what absolute limits there are on government policy is essential if we are not to defer power to technocrats, or lose it to demagogues.

Of course, it would be fair to say that 'travelling light' when it comes to principle is so old it is practically in the national DNA, and could be described as a strength. ${ }^{\text {xiv }}$ Take British gun laws. The stridency of America's second amendment compares to the more indeterminate article seven of the Bill of Rights 1688: 
'...the right of the people to keep and bear Arms, shall not be infringed.'

'That the Subjects which are Protestants may have Arms for their Defence suitable to their Conditions and as allowed by Law.'

Notwithstanding that 'A well regulated Militia' is open to interpretation, America's gun laws are reasonably fixed. Britain's approach, conversely, was to ensure the state could, at any time, take away its citizens' guns. This was achieved with conditional language (which, and as) and adjectives (suitable). The mere presence of this sort of indeterminacy in legislation would not in itself be interesting, but its increased use is. A majority of sections of contemporary legislation use indeterminate language.

The normative implications are that power is not controlled by society. Clear statements on what future we want are essential if democracy is not to be overwhelmed by circumstance and discretion. So what counts as good legislation must consider the language used, and not just its substance. Parliamentary reforms allowing for pre-legislative scrutiny and evidence-gathering public bill committees are positive steps in this direction. All of which is not to say that the civil service bill teams and Parliamentary Counsel who draft the laws in the first place are responsible. The civil service produce what their government clients demand. And, indeed, modern legislative language is a genre. It has norms of construction that are not easily ignored. Individual drafters cannot simply sharpen up the language without concerted effort from their political bosses. 
Various solutions are available. An interim solution would be for governments to clarify a theory that guides their decision-making. Modern policy is less drawn from any vision of the public good and is more 'muddling through' and reacting to events. ${ }^{\mathrm{xv}}$ By making clear what vision of the future is preferred, politicians can shape events and not simply react to them. But, more lasting change will come with constitutional reform. Institutions could close the gap between public demand for and government supply of power by facilitating a more honest dialogue. Voters need to be more aware of supply-side constraints and politicians need to be less able to win elections by pandering. A more participatory model of law making could be achieved with proportionate election rules, greater devolution to local communities and even the use of citizen assemblies to make decisions. ${ }^{x v i}$ These could lead to some messy compromises in language, but they would likely curtail the capacity of governments and powerful individuals to determine the meaning of legislation. Furthermore, immutable rights set in a codified constitution would offer a better sense of what words can and cannot mean. ${ }^{\text {xvii }}$

\footnotetext{
Notes

${ }^{\mathrm{i}}$ Hence the reference in the essay title to H.J. Laski, A grammar of politics. London: G. Allen \& Unwin, 1938.

ii V.A. Schmidt, 'Discursive institutionalism: The explanatory power of ideas and discourse', The Annual Review of Political Science, vol. 11, 2008, pp. 303-26.

iii M. Williams, 'What effect does legislative language have on policy delivery? A natural experiment of homelessness provision in England and Wales.', forthcoming.

iv Hotak v London Borough of Southwark [2015] UKSC 30.

${ }^{\mathrm{v}}$ G. Tsebelis, and D. Nardi, 'A long constitution is a (positively) bad constitution: Evidence from OECD countries.' British Journal of Political Science, vol. 46, 2016, pp. 457-478.

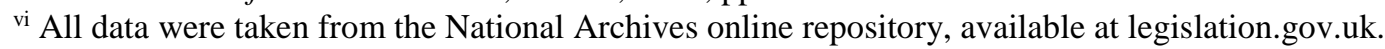

vii J. Huber, and C. Shipan, Deliberate discretion? The institutional foundations of bureaucratic autonomy. Cambridge: Cambridge University Press, 2000.

viii C. Hood, 'A public management for all seasons.' Public Administration, vol. 69, no. 1, pp. 3-19.

${ }^{\text {ix }}$ P. Dunleavy, R.A.W. Rhodes, and B. O'Leary, Prime Minister, Cabinet and core executive. Oxford: Blackwell, 1990.

${ }^{x}$ A. Gamble, The free economy and the strong state: The politics of Thatcherism. Basingstoke: Macmillan, 1988.

${ }^{\mathrm{xi}}$ H.S. Maine, Ancient law : its connection with the early history of society and its relation to modern ideas. London: John Murray, 1861.

${ }_{\text {xii }}$ C. Anderson, Losers' consent: Elections and democratic legitimacy. Oxford: Oxford University Press, 2005.

xiii C. Crouch, Post-democracy, Cambridge, Polity, 2004.

xiv To paraphrase Ian Gilmour.
} 
${ }^{x v}$ C.E. Lindblom, 'The science of "muddling through".' Public Administration Review, Vol. 19, No. 2, pp. 79-88, 1959.

${ }^{x v i}$ K. Dowding, J.D. Wispelaere, and S. White, eds, The ethics of stakeholding. Basingstoke: Palgrave Macmillan, 2003.

xvii I. McLean, What's wrong with the British constitution? Oxford, Oxford University Press, 2010. 